This PDF is a selection from a published volume from the National Bureau of Economic Research

Volume Title: Targeting Investments in Children: Fighting Poverty When Resources are Limited

Volume Author/Editor: Phillip B. Levine and David J. Zimmerman, editors

Volume Publisher: University of Chicago Press

Volume ISBN: 0-226-47581-6

ISBN13: 978-0-226-47581-3

Volume URL: http://www.nber.org/books/levi09-1

Conference Date: September 26, 2008

Publication Date: August 2010

Chapter Title: Neighborhood and Community Initiatives

Chapter Authors: Julia Burdick-Will, Jens Ludwig

Chapter URL: http://www.nber.org/chapters/c11731

Chapter pages in book: (303 - 321) 


\title{
Neighborhood and Community Initiatives
}

\author{
Julia Burdick-Will and Jens Ludwig
}

\subsection{Introduction}

Educational outcomes vary dramatically across neighborhoods in America. For example, in the Chicago North-shore suburb of Wilmette, where the median home value is $\$ 441,000$ and only 2 percent of residents live below the poverty line, almost everyone graduates from high school and a majority go on to attend - and even complete - college. In contrast, the dropout rate in the Chicago Public Schools is well over 40 percent (Allensworth and Easton 2001), and is even higher in some of Chicago's most disadvantaged neighborhoods on the South and West Sides.

Why are children who grow up in disadvantaged areas at such elevated risk for educational problems, even beyond what we would predict based on their own family circumstances? The answer is important in part because of the persistence of concentrated urban poverty in America. Residential segregation by income has been increasing since 1970 (Watson 2009); in 2000 there were 8 million people living in high-poverty Census tracts $(\geq 40$ percent), nearly twice the number as in 1970 (Jargowsky 2003). Because blacks are much more likely than whites to live in high-poverty neighborhoods, even controlling for family poverty status (Jargowsky [1996, 2003]; see also Massey and Denton [1993] and Massey [1996]), there is concern that

Julia Burdick-Will is a doctoral candidate in sociology at the University of Chicago. Jens Ludwig is the McCormick Foundation Professor of Social Service Administration, Law, and Public Policy at the University of Chicago, a Non-resident Senior Fellow in Economic Studies at the Brookings Institution, and a research associate and co-director of the working group on the Economics of Crime at the National Bureau of Economic Research.

Thanks to Jeffrey Kling, Phillip Levine, Stephen Raudenbush, Robert Sampson, Lisa Sanbonmatsu, Patrick Sharkey, David Zimmerman, and an anonymous referee for useful comments. Any errors and all opinions are our own. 
"neighborhood effects" contribute to the overall test score disparities observed between rich and poor children or between blacks and whites (see, for example, Wilson [1998]).

One reason that neighborhood residence might impact children's achievement outcomes is because of variation across areas in the quality of local public schools. Another possible explanation focuses on the influence of peers and other neighborhood residents. Distinguishing between these two competing explanations is important for the design of antipoverty policies. If social context influences children's life chances, then education policies that break the link between neighborhood residence and school assignments, or housing policies that help poor families move to lower-poverty areas, may be an important strategy for improving the achievement outcomes of low-income children. On the other hand, if neighborhood effects on children's outcomes are driven mainly by the quality of local institutions, then in principle it may be possible to design community-level interventions that improve achievement without having to re-sort poor children across social environments.

Empirical claims for the powerful effect of neighborhood context on children's schooling outcomes dates back at least to the landmark Coleman Report, which argued that "attributes of other students account for far more variation in the achievement of minority group children than do any attributes of school facilities and slightly more than do attributes of staff" (Coleman 1966, 302). These findings, if taken at face value, would seem to imply the existence of powerful neighborhood effects on children's learning, given school composition is determined in large part by neighborhood composition. However, drawing causal inferences from this type of nonexperimental research on peer or neighborhood effects is complicated by the fact that most families have at least some degree of choice over where they live. These studies may confound the causal effects of social context with those of unmeasured family attributes that affect both educational outcomes and residential location.

This chapter will review the available evidence about neighborhood effects on children's achievement outcomes, and the degree to which "place-based" policies might help improve outcomes for poor children and reduce disparities across race and class lines. Our study focuses mostly on those studies that exploit the substantial excess demand for means-tested housing subsidies, and in particular housing vouchers, which provide a source of identifying variation in neighborhood environments across observably similar low-income families that helps overcome the self-selection concerns with previous research in this area. There is a large literature that examines the effects of community development interventions such as urban enterprise zones (see, for example, Ladd [1994], or Busso and Kline [2007]) or policing interventions (Sherman 2001), but almost none of this literature examines 
impacts on children's outcomes. ${ }^{1}$ In discussing the policy value of the housing voucher research literature, Heymann and Fischer $(2003,344)$ noted that "the best solution-oriented research to date has been conducted on moving people out of hard-hit neighborhoods."

Previous research suggests that offering housing vouchers to low-income families who already live in private-market housing does not lead these families to move to substantially different types of neighborhoods (see Olsen [2003]; Jacob and Ludwig [2009]). On the other hand, housing vouchers do enable families living in public housing to move to less disadvantaged, dangerous, and socially disorganized neighborhoods. Historically, public housing units have been disproportionately likely to be located in high-poverty urban neighborhoods (Jencks and Mayer 1990; Massey and Denton 1993; Wilson 1987). In order to receive help with their housing needs, low-income families have to live in the neighborhoods in which public housing projects have been developed. Housing vouchers instead provide low-income families with some additional choice over where they live. We focus our attention mostly on studies of a single, clearly defined, and quite important policy question - what happens to the academic outcomes of poor children in public housing when their families are offered the chance to move somewhere else with a housing voucher.

The existing research paints a somewhat complicated picture of what "vouchering out" public housing might do to the academic outcomes of low-income children. There is some evidence that voucher-induced moves to lower-poverty neighborhoods may improve the academic achievement outcomes of African American children in some cities, but not in others. Why impacts vary across cities remains unclear. On the other hand, the research is more clear that using housing vouchers to help public housing families move to less distressed areas can improve other key outcomes such as mental health and criminal behavior, which may in turn improve labor market outcomes and are of course also key contributors to well-being in their own right as well.

The remainder of our chapter is organized as follows. The next section discusses the different behavioral mechanisms through which voucherinduced neighborhood moves might affect the academic outcomes of poor children. The third section provides some additional discussion of the housing voucher program rules, and notes that the government monetary costs of vouchering out public housing may be negative - that is, most housing economists believe that housing vouchers cost less than public housing in providing a given level of housing unit quality to a family. Section four reviews the available empirical evidence, the fifth section discusses potential

1. One recent exception is Dobbie and Fryer's (2009) study of the effects of the Harlem Children's Zone on children's academic achievement test scores. 
voucher effects on other outcomes that are relevant for social welfare, while the sixth section concludes.

\subsection{Conceptual Framework}

Since the early days of the "Chicago School," sociologists have theorized about the ways in which neighborhood environments may impact child development. Early theories emphasized the role of social disorder and the ecological competition for resources. These early scholars viewed the city in terms of an urban ecology in which different ethnic groups, in various stages of assimilation and economic integration, compete for vital resources and niches in neighborhoods, in the same way that species compete in the natural world. Therefore, the most disadvantaged populations naturally end up in the least desirable locations and disproportionately are exposed to high crime, limited institutional resources, and the physical dangers and health risks of the zones closest to industry (Park, Burgess, and McKenzie 1967).

Furthermore, the early sociological literature saw the urban environment as a place where the density and heterogeneity of the population contributed to the disruption of strong social ties that may help maintain order and deter deviant behavior, such as crime and poor school performance, in small towns (Simmel 1997; Wirth 1997). This was especially true in the "slums," where high residential mobility and large numbers of family-less individuals further contributed to the deterioration of the social and moral order (Zorbough 1983). While current research has largely abandoned these relatively deterministic models of human ecology, there remains a great deal of interest in the potential relationship between neighborhood environments and children's life chances.

In their 2002 review of neighborhood effects, Harvard sociologist Robert Sampson and his colleagues identify four general social processes through which neighborhood characteristics are currently thought to affect those who live in them (Sampson, Morenoff, and Gannon-Rowley [2002, 457-8]; see also Jencks and Mayer [1990]). First, the social ties and interpersonal interactions with coresidents in a neighborhood provide different opportunities to accumulate social capital. In terms of school outcomes, children living in poor neighborhoods may have diminished access to well-educated adults to help them with homework or act as pro-academic role models (Wilson 1987, 1996). Parents in poor neighborhoods may also be less involved in their children's schools and less able to activate the social capital necessary to advocate for school improvement (Coleman 1991). Moreover, children's peer groups often come overwhelmingly from their neighborhood. Prosocial and antisocial neighborhood peer groups may influence student achievement either directly by affecting the level of instruction in the classroom (Hoxby 2000; Zimmer and Toma 2000), or indirectly by shaping the social rewards to pro- versus antisocial behavior (Gavaria and Raphael 2001). 
Second, neighborhoods may influence school outcomes not through the direct ties of the residents, but through their social norms and capacity for informal social control (Sampson, Morenoff, and Earls 1999). In other words, it may not be who the local children know directly, but rather the general levels of trust and expectations for behavior that prevail in the neighborhoods. For example, children may be less likely to get into trouble that would interfere with school when their neighbors are willing to intervene and keep an eye out for them. High expectations about overall educational attainment and achievement may also lead students to be more willing to work hard in school.

Third, the quantity and quality of neighborhood institutional resources may matter. When it comes to academic achievement, neighborhood schools are probably the most important — but not the only relevant — local institutions. Resources ranging from adequate medical care facilities, child care centers, parental employment opportunities, and after-school social and academic organizations could all influence children's academic performance in potentially important ways (Jencks and Meyer 1990; Brooks-Gunn et al. 1993).

Finally, children's routine activities and those of their neighbors are shaped by the geography of neighborhoods, and may also have a direct influence on student achievement. Land use, such as the presence of bars, parks, or highrise versus single-family homes, may shape the type of people that children interact with and the types of places in which they can interact with their peers (Sampson, Sharkey, and Raudenbush 2008). These ecological factors may also have a direct impact on the safety level of the neighborhood by, for instance, affecting the degree to which public spaces can be easily monitored by police or community residents (Jacobs 1997). Furthermore, the patterns of adult activity that children experience on a daily basis may also affect their own behavior in and outside of school, which may indirectly impact their achievement levels. For example, children who observe their parents and neighbors coming and going regularly to work and attend formally organized activities during the standard workday may more quickly learn the value of routine and punctuality needed to excel in school. They may also learn how to navigate the world of formal interactions and organizations, such as schools, better than children who spend their time playing informally in the street (Lareau 2003).

Implicit in most of the aforementioned mechanisms is the assumption that "better" (i.e., less poor or otherwise disadvantaged or distressed) neighborhoods should always lead to improvements in child achievement. However, especially when considering housing voucher programs, it is important to note that this need not necessarily be the case. For example, Small and Stark (2005) find that poor neighborhoods often have more vital resources appropriate to low-income households, such as affordable child care centers, than more affluent neighborhoods. It is possible that, just like child care 
centers, the after-school resources available for children in poor neighborhoods may be more affordable and accessible than those in their new more affluent neighborhoods. Furthermore, feelings of relative deprivation and low social and academic standing with respect to their new neighbors and classmates may be discouraging to students and reduce the effort they make in school, or make them less happy with potentially adverse consequences for their schooling engagement and outcomes (Jencks and Meyer 1990; Luttmer 2005).

In sum, there are many reasons to theorize that moving children out of poor neighborhoods may improve their test scores and school outcomes. But there are also reasons to hypothesize that voucher-assisted moves to less distressed areas may not produce the desired outcomes. This means that the actual impact of moving children to less disadvantaged areas is ultimately an empirical question.

\subsection{The Housing Voucher Program}

Housing vouchers subsidize low-income families to live in private-market housing. ${ }^{2}$ Eligibility limits for housing programs are a function of family size and income, and have been changing over time. Since 1975 an increasing share of housing assistance has been devoted to what the U.S. Department of Housing and Urban Development (HUD) terms "very low-income households," with incomes for a family of four that would be not more than 50 percent of the local median. (The federal poverty line is usually around 30 percent of the local median.) The maximum subsidy available to families is governed by the Fair Market Rent (FMR), which equaled the forty-fifth percentile of the local private-market rent distribution through 1995, was lowered to the fortieth percentile in 1995, and then in 2001 selected metropolitan areas, including Chicago, have been allowed to set FMR equal to the fiftieth percentile. For example, the FMR for a two-bedroom apartment in the Chicago area was equal to $\$ 699$ in $1994, \$ 732$ in 1997 , and $\$ 762$ in 2000 .

Families receiving vouchers are required to pay 30 percent of their adjusted income toward rent. Adjusted income is calculated by subtracting from a family's (reported) gross income deductions of $\$ 480$ per child, $\$ 400$ per disabled member of the household, child care expenses, and medical care expenses over 3 percent of annual income. Temporary Assistance for Needy Families (TANF) is counted toward the calculation of gross income, but Earned Income Tax Credit (EITC) benefits and the value of Food Stamps, Medicaid, and other in-kind benefits are not counted. The voucher covers the difference between the family's rent contribution and the lesser of the FMR or the unit rent. Starting in 1987, the government made these tenant-

2. This discussion is based on the excellent, detailed and highly readable summary in Olsen (2003). 
based subsidies "portable," meaning that families could use them to live in a municipality different from the one that issued them the subsidy.

As noted before, housing assistance is not an entitlement. In Chicago, as in other big cities, there are generally extremely long waiting lists to receive housing assistance, especially for housing vouchers. Once a family receives a housing voucher they can keep the subsidy for as long as they meet the program's income and other eligibility requirements.

Despite the excess demand for housing vouchers, not all families offered vouchers wind up using them. Many apartments have rents above the FMR limit, some landlords may avoid renting to voucher families, ${ }^{3}$ and families offered vouchers have a limited time (usually three to six months) to use the voucher to lease up a unit. Mobility outcomes in voucher programs are affected by family preferences as well as housing market constraints - that is, both the demand and supply sides of the housing market are relevant. Relatively little is known at present about what sorts of information families have available to them about different neighborhood options, or what types of neighborhood attributes factor most importantly into the mobility decisions of voucher families.

There are currently around 1.95 million households receiving housing vouchers to rent privately-owned units, 1.1 million households living in public housing, and an additional 1.4 million or so households living in other project-based housing units. ${ }^{4}$ Just under two-thirds of housing voucher recipients are families with children, about twice the number of families with children living in public housing. ${ }^{5}$

Olsen's (2003) review of the available housing research argues that the costs to the government of providing low-income families with a housing unit of given quality is lower with the housing voucher program than with project-based programs such as public housing or Section 8 project-based housing (basically privately-operated public housing), perhaps by as much as 20 percent or more. Among the potential explanations include the potentially greater efficiency with which private-market landlords may operate housing units compared to project-based units. If this view is correct, ${ }^{6}$ then

3. Some landlords may avoid renting to voucher families because of the paperwork requirements, the program's minimum housing quality standards (which must be verified by an inspection, although failed units can be modified and re-inspected), and a previous rule that has since been abolished that limited the ability of landlords to turn away future voucher applicants ("take one, take all").

4. Housing voucher figures are for early 2007 calculated by the Center on Budget and Policy Priorities (www.centeronbudget.org/5-15-03hous.htm, accessed 1/12/09). Data on public housing figures are from www.cbpp.org/10-11-06hous.htm, accessed on 1/12/09, while figures on other project-based housing comes from www.gao.gov/new.items/d07290.pdf, p. 14, accessed on $1 / 12 / 09$.

5. Counts of families receiving vouchers have been estimated using the total number of units available and the percent of those units occupied by different family types. Source: A Picture of Subsidized Housing - 2000, http://www.huduser.org/picture2000/.

6 . There does remain some debate in the literature on this point; see for example McClure (1998) versus Shroder and Reiger (2000). 
the budget cost to the government of vouchering out public housing may be negative - that is, this policy may wind up saving government money.

It is important to recognize, however, that some of the most important costs of vouchering out public housing may be nonmonetary. Specifically, if housing vouchers help public housing children by exposing them to more affluent and prosocial peers, then in principle, vouchering out public housing could have some adverse impact on the academic outcomes of children in destination neighborhoods. In the next section we discuss these sorts of peer mechanisms in more detail, and return in the conclusion to this chapter to what is known about any adverse peer impacts on children living in areas that experience an influx of vouchered-out public housing families.

What would it cost to move the other (nonpublic housing) children from high-poverty areas into less economically disadvantaged neighborhoods? The answer is that we currently do not know. As noted in the introduction, previous research has found that giving housing vouchers to low-income families who are already living in private-market housing does not lead them to move into different types of neighborhoods. These housing voucher subsidies typically represent a very large share of the family's total income-for example, on the order of 75 percent among all families applying for housing vouchers in Chicago in the late 1990s (Jacob and Ludwig 2009). It is possible that "super vouchers" that provide families with intensive extra supports to negotiate the housing market or incentives to move into particular types of neighborhoods could lead to more pronounced effects of vouchers on mobility outcomes. While these types of "super vouchers" have been offered in the past to public housing families (as part of the Moving to Opportunity [MTO] experiment discussed following), we know of no study that has offered these types of enhanced vouchers to families who were already living in private-market housing. The question of what it would take to help move low-income private-market families from high- to low-poverty neighborhoods is an important one for public policy, given that the majority of lowincome children (and even of low-income children living in high-poverty areas) do not live in public housing.

\subsection{Empirical Evidence}

Measuring the causal effect of neighborhood environments on children's school outcomes is complicated by the fact that most families have at least some degree of choice over where they live. This raises the possibility that observational studies may confound the causal effects of neighborhood environments on children with those of hard-to-measure family attributes that are associated with residential sorting. As a result of this concern about neighborhood selection, much of the evidence for neighborhood effects on academic achievement has come from a few key natural or randomized experiments and a few unusually rich observational data sets. 
The first quasi-experimental study of the effects of neighborhoods on school outcomes arose out of a 1966 lawsuit filed by a Chicago public housing resident named Dorothy Gautreaux (see table 11.1). Her lawsuit claimed that the Chicago Housing Authority (CHA) and U.S. Department of Housing and Urban Development (HUD) did not provide adequate opportunities for public housing residents in Chicago to live in racially integrated neighborhoods. The case eventually reached the U.S. Supreme Court, which in 1976 ruled in her favor.

As a result of the Supreme Court's ruling, what came to be known as the Gautreaux program began offering public housing residents the opportunity to use housing vouchers in racially integrated neighborhoods (less than 30 percent black) in the city and suburbs. Participants who volunteered for the program were assigned housing based on where there happened to be openings. Once the program was fully established in the 1980s, around 1,700 to 2,000 families a year signed up to participate, out of whom about 19 percent of those, or 300 families a year, were placed in racially and economically integrated, mostly suburban, neighborhoods using the vouchers (Rubinowitz and Rosenbaum 2000, 67). Many of the remaining families wound up being placed in neighborhoods that were still poor and segregated, but judged to be improving, which were usually located within the Chicago city limits (Mendenhall, DeLuca, and Duncan 2006). While in theory, participants could choose not to accept the housing units assigned to them, most families reportedly accepted the first available apartment (Kaufman and Rosenbaum 1992).

In 1988, a random sample of 342 Gautreaux participants was surveyed in an attempt to compare the suburban movers with those who had stayed in the city of Chicago. The surveyed families had enrolled in the Gautreaux program between 1976 and 1981, and so were surveyed from seven to twelve years after their Gautreaux-assisted neighborhood moves. Compared to the surveyed students who remained in the city of Chicago, suburban movers were four times less likely to have dropped out of school (20 percent versus 5 percent); more likely to be in a college track in high school ( 24 versus 40 percent); twice as likely to attend any college ( 21 percent versus 54 percent); and almost seven times as likely to attend a four-year college (4 percent versus 27 percent). The only educational attainment measure for which the suburban students did not appear to be doing significantly better than the city students was their grade point average, which could simply reflect higher grading standards in suburban schools (Rubinowitz and Rosenbaum 2000, 134-6).

While the Gautreaux program results were quite encouraging, there necessarily remains some question about whether the Gautreaux families surveyed in the suburbs were comparable in all respects to the surveyed city movers. For example, there is now some evidence that the initial residential placements of Gautreaux families is systematically correlated with the characteristics of families and their neighborhoods at baseline (Mendenhall, 


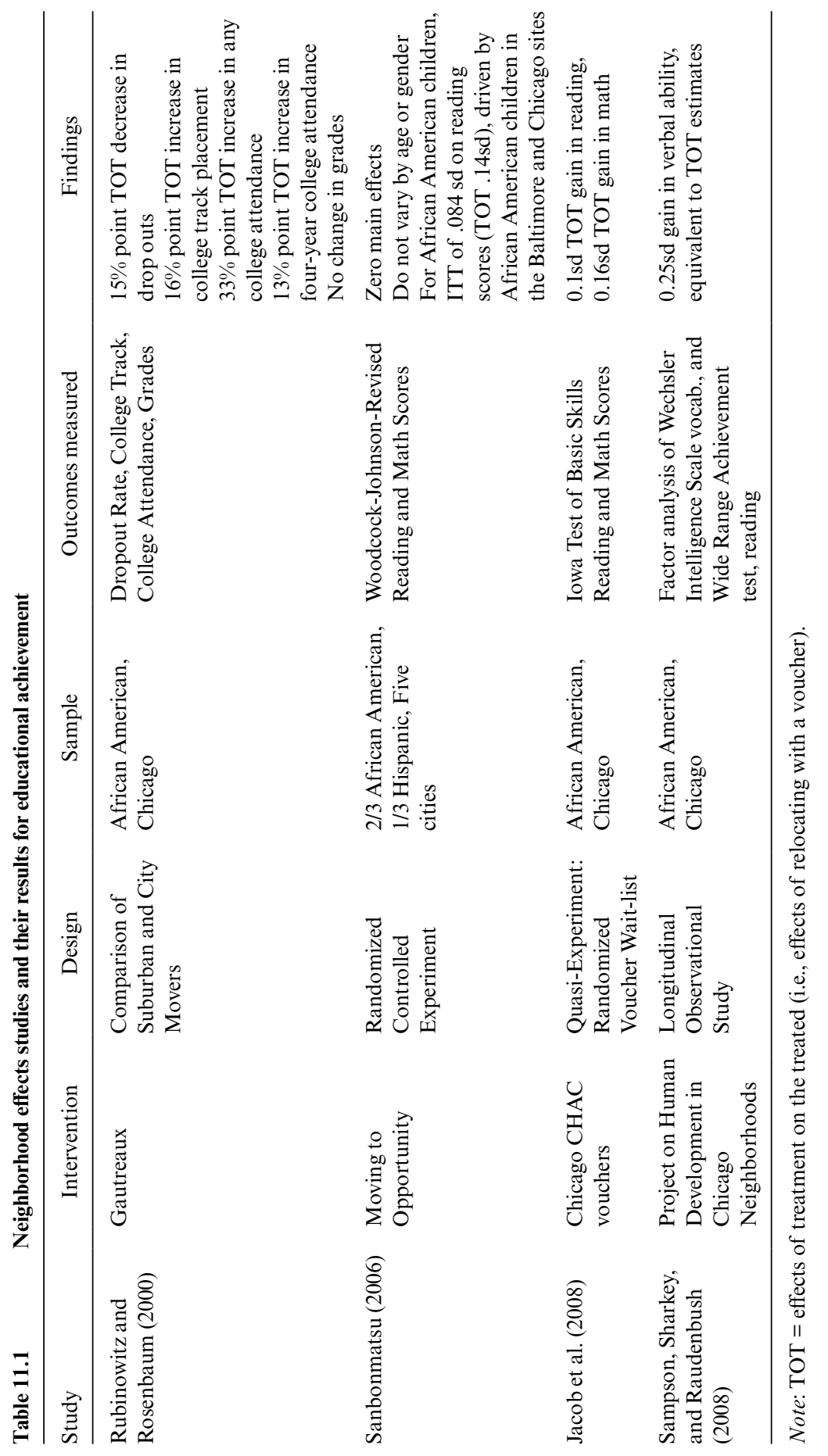


DeLuca, and Duncan 2006; Votruba and Kling 2009). It is possible that at least part of the differences in schooling outcomes observed between city and suburban movers in Gautreaux are due to differences in the background attributes of the families who are being compared.

In response to the apparent success of the Gautreaux program, federal funding was allocated for a true housing voucher experiment designed to test the effects of neighborhood poverty called Moving to Opportunity (MTO). Between 1994 and 1998, a total of 4,600 low-income, mostly minority public housing residents in five U.S. cities (Chicago, New York, Boston, Baltimore, and Los Angeles) signed up to participate in the MTO program. Through a random lottery, families who signed up for MTO were assigned to one of three different residential mobility groups. Families assigned to the Experimental group were awarded a housing voucher that could be used for private housing only in a low-poverty area (census tracts with 1990 poverty rates of less than 10 percent), and were also given counseling and assistance in finding their new apartment. Families assigned to the Section 8-only group were given a standard Section 8 housing voucher that could be used in any census tract in which the family wished to live and could find a suitable unit to lease. Families assigned to the Control group did not receive a voucher of any kind, but maintained their current project-based housing and their eligibility for whatever other social programs they were receiving (Orr 2003).

Of the families assigned to the experimental group, around 47 percent relocated with a housing voucher through MTO while 62 percent of those assigned to the Section 8-only group relocated through MTO. Many of the families who moved through the MTO experimental group to a low-poverty tract eventually moved again and returned to higher-poverty neighborhoods, while some families in the control group relocated on their own, even without MTO assistance. Nevertheless, random assignment to the MTO experimental rather than control group generates large differences in residential neighborhood characteristics, with differences in tract poverty rates equal to 25 to 30 percent of the control mean one year after random assignment and around 20 to 25 percent over the six years after assignment. The MTO generates similarly large changes in other measures of neighborhood socioeconomic composition, safety, social disorder, and social cohesion, but leads to more modest changes in neighborhood racial composition.

Data on children's outcomes collected on average five years after random assignment found that on average there is no statistically significant effect of MTO-induced moves on children's scores on the Woodcock-JohnsonRevised reading or math achievement tests (Sanbonmatsu 2006). The estimates do not seem to be any larger for children who were relatively younger at the time of baseline. However, it is important to keep in mind that these achievement test scores were recorded just five years after baseline, and so many of those children who were very young at the time of random assignment (and so could potentially benefit the most from MTO moves; see, for 
example, Shonkoff and Phillips [2000] and Knudsen et al. [2006]) were still too young to be tested at the time of the interim MTO evaluation.

Additional subgroup analyses find that there might be some effect of being assigned to the experimental rather than control group on the reading test scores of African American children, with an intent to treat effect (ITT) equal to around 0.1 standard deviations so that the effect of actually using a voucher is more like 0.2 standard deviations (Sanbonmatsu 2006, Web Appendix). However, these impacts seem to be driven by African American children in just two of the five MTO sites-Baltimore and Chicago, where almost all of the MTO program population is African-American, although only the Baltimore results are statistically significant. ${ }^{7}$ In the other three MTO cities (Boston, Los Angeles, and New York) the program sample is split between African American and Hispanic children, and separate subgroup analyses reveal no statistically significant gains in test scores for either black or Hispanic children. ${ }^{8}$

Given the large number of subgroup estimates generated with the MTO achievement test analysis, it is possible that the hints of reading score gains for African American children in the Baltimore and Chicago MTO sites could be "false positives" - that is, if we simply generate enough estimates, at least one may be significant at the 5 percent cutoff just by chance alone. Some support for the idea that African American children in Baltimore and Chicago MTO might really have improved reading scores comes from a more recent study, which analyzes data on every public housing family in Chicago who applied to the city's regular housing voucher program when the program's wait-list was opened in 1997 for the first time in a dozen years (see Jacob et al. 2009b).

In total, 82,607 eligible families applied, far more than the number of vouchers that were available, with around 10 percent of all applicants living in public housing at the time they applied. The firm running the city's housing voucher program at the time, CHAC Inc., randomly assigned all families who applied for a voucher to a position on the voucher wait-list. Given the random assignment of families to the voucher program wait list, the causal effects of vouchering out public housing can be estimated with this larger

7. Ludwig, Ladd, and Duncan (2001) analyzed short-term achievement test scores measured two to three years after random assignment for children in the Baltimore MTO site and found very sizable gains in test scores for children who relocated through the MTO demonstration. The site-specific analyses in the interim (five year) MTO study, which examined data from all five MTO sites, suggest the way to reconcile the short-term and interim results is site heterogeneity in MTO impacts rather than "fade out" of MTO test gains.

8. While the estimated experimental treatment impact on reading scores is not statistically significant in either the Baltimore or Chicago site when analyzed separately, the impact is significant when data from those two sites are pooled together. In contrast the estimated impacts of MTO experimental group assignment on reading or math scores are very small both absolutely and relative to the standard errors when data from the other three MTO sites (Boston, Los Angeles, and New York) are pooled together and analyzed overall or analyzing African American and Hispanic children separately. Thanks to Jeffrey Kling for his helpful discussions on this point. 
Chicago housing voucher sample in the same way as in the randomized MTO experiment, by basically comparing the outcomes of those children whose families were assigned good versus bad wait-list positions.

As in the MTO experiment, families in Chicago who lived in public housing at baseline and were offered vouchers wound up moving to neighborhoods that were less economically segregated than those of families who were not offered vouchers, but these areas were not less racially segregated. Children in the families who relocated with a voucher experienced gains on their Iowa Test of Basic Skills (ITBS) reading and math assessments equal to 0.16 standard deviations relative to their control group counterparts (Jacob et al. 2009a).

Similar evidence comes from nonexperimental analyses of data from the Project on Human Development in Chicago Neighborhoods (PHDCN). While the PHDCN is an observational, not experimental study, the longitudinal structure of the data and the rich set of observable covariates help generate correlational estimates that are a useful complement to those from MTO and CHAC. The PHDCN is a longitudinal study of a random sample of approximately 3,000 children ages zero to eighteen at wave one, in randomly selected Chicago neighborhoods. The children are followed for three waves over seven years to wherever they moved in the United States. Sampson and his colleagues exploit the longitudinal nature of the data and the rich set of covariates to predict selection into and out of disadvantaged neighborhoods and then use those predicted probabilities to estimate the effect of moving out of a disadvantaged neighborhood (Sampson, Sharkey, and Raudenbush 2008).

The explanatory variable of interest in their analysis is a measure of "concentrated disadvantage" that comes from a factor analysis of the concentration of welfare receipt, poverty, unemployment, female-headed households, African Americans, and children under eighteen years old (Sampson, Sharkey, and Raudenbush 2008, 848). In Chicago, the only ethnic group in the sample living in neighborhoods with the most extreme levels of concentrated disadvantage (the bottom quartile of the Chicago distribution) is African Americans. Therefore, Sampson, Sharkey, and Raudenbush restrict their analysis only to African American children, and find that children who leave severely disadvantaged neighborhoods experience a 0.25 standard deviation increase in their later verbal test scores (a combination of the Wechsler Intelligence Scale vocabulary test and the Wide Range Achievement reading test) compared to other African American children in the PHDCN (Sampson, Sharkey, and Raudenbush 2008).

\subsection{Other Effects of Housing Voucher Programs}

Regardless of the direct effect of housing vouchers on test scores, a number of other social benefits seem to arise from providing public housing families with housing vouchers to move to less disadvantaged neighbor- 
hoods. One of the most robust findings from MTO was that program moves substantially improved the mental health of females, with impacts on parent depression that are about as large as current best-practice antidepressant drug treatment and even larger gains in mental health for female youth (Kling, Liebman, and Katz 2007). ${ }^{9}$ These reductions in mental health problems appear to be linearly related to the poverty level of the neighborhood that the women move to; that is, the greater the reduction in neighborhood percent poor, the greater the impact of the move on the mental health of female adults and youth. Interestingly, MTO moves did not seem to generate similar improvements in mental health for male youth. It is still unclear exactly why there are such stark gender differences, but it may have to do with the different ways in which male and female youth adjusted to their new environments and peers (Kling, Ludwig, and Katz 2005; ClampetLundquist et al. 2006).

The MTO moves have also been demonstrated to reduce the social costs of criminal activity by program youth (Kling, Ludwig, and Katz 2005). Female youth experience large reductions in arrest rates for all types of offenses. Female youth who moved with the voucher, were on average approximately 85 percent less likely to be arrested for any kind of crime than were controls. The relative declines in violent and property crime arrests specifically were equal to 76 and 85 percent. The results for males are mixed, with declines in violent crime arrests but large increases (equal to 76 percent of the control mean) in property crime arrests. Because the costs to society from violent crimes are far larger than those from property offenses, the net effect of relocating with a MTO experimental group voucher is to reduce the social costs of crime from around $\$ 3,000$ to $\$ 25,000$ per youth, depending on the age of the sample and the measure of the costs of crime that is used (Kling, Ludwig, and Katz 2005).

\subsection{Conclusion}

Taken together, the available evidence seems to suggest that using housing vouchers to move African American public housing children into less distressed areas can improve their achievement test scores, at least in some cities. In different Baltimore and Chicago samples the Treatment on the Treated (TOT) impacts of voucher utilization is on the order of .1 to .2 standard deviations, which is in the same ballpark as the famous Tennessee Student Teacher Achievement Ratio (STAR) class-size reduction experiment (Krueger 1999). Why housing voucher moves should help boost the test scores of African American children in Chicago, and perhaps Baltimore,

9. Mothers in experimental group who moved were 13 percent more likely to report feeling calm and peaceful and 0.2 standard deviations lower on a scale of psychological distress than the mothers in the control group. On average, young females who moved were a full 0.59 standard deviations lower on the psychological distress scale than those who were not offered a voucher and 13 percent less likely to have symptoms of generalized anxiety disorder. 
but not for either black or Hispanic children in the other MTO cities remains a mystery.

On the other hand, voucher-induced moves into less distressed areas improves other outcomes such as mental health, crime victimization, and socially costly criminal behavior that may influence labor market outcomes. Of course, since the ultimate goal of social policy is to improve the wellbeing of families rather than simply change their incomes relative to the federal poverty line, impacts on health and crime are important outcomes in their own right as well.

Unfortunately relatively little is currently known about what specific mechanisms underlie the observed impacts of voucher-assisted neighborhood moves. The MTO treatment group assignment improves neighborhood socioeconomic composition, generates relatively modest changes in neighborhood racial composition or school quality, and large changes in safety. Because MTO randomization generates large changes in multiple candidate mechanisms simultaneously, it is not possible to determine the independent causal contribution of each potential behavioral pathway. There is some evidence that criminal behavior among MTO participants may have declined the most in demonstration sites where MTO families experienced the largest changes in neighborhood racial segregation (Ludwig and Kling 2007), but this does not seem to be the case for achievement test scores.

The other key question that remains with vouchering out public housing has to do with the costs. Our reading of the housing economics literature suggests that housing vouchers are probably more cost-effective than project-based housing programs, at least with respect to the government financial costs. But perhaps the most important costs associated with vouchering out public housing could be nonmonetary, in the form of potential adverse peer effects on children who are living in the destination neighborhoods to which voucher families relocate. If relocating from a high-poverty to a low-poverty neighborhood might generate positive impacts on the poor children who move, then it must be logically possible that such moves could adversely impact the children in the receiving low-poverty areas. How vouchering out effects overall aggregate test scores will depend on whether any peer influences on achievement vary linearly or nonlinearly with neighborhood poverty, and on whether different types of children respond similarly or differently to the same types of neighborhood environments. To date, almost nothing is known about this important question since the voucher mobility work is largely dominated by studies of just those children who move. ${ }^{10}$

10. Some indirect evidence on this question comes from studies of what happens to property values in neighborhoods into which housing voucher families move. For example, in a case study of Philadelphia, Lee, Culhune, and Wachter (1999) find that concentrations of voucher recipients in a neighborhood lead to small property value reductions, which are much smaller than those predicted by the construction of new public housing projects. Whether these property value impacts reflect actual adverse peer influences on children, or instead, a form of statistical discrimination is currently not known. 
Most parents probably believe that neighborhood environments matter to some degree for how their children turn out, and certainly few parents who could avoid it would wish their children to grow up in the housing projects found in some of our nation's most disadvantaged and dangerous urban neighborhoods. Existing research suggests that, not surprisingly, helping families move out of dangerous, high-poverty housing projects improves the safety and well-being of parents and children, and even reduces the net social costs of criminal activity committed by children in these families. But whether vouchering out housing projects across the country would generate large changes in children's achievement test scores, and subsequently help them earn enough to avoid poverty during adulthood, remains unclear.

\section{References}

Allensworth, E., and J. Q. Easton. 2001. Calculating a cohort dropout rate for the Chicago public schools: A technical research report. Chicago, IL: Consortium on Chicago School Research, June.

Brooks-Gunn, J., G. J. Duncan, P. K. Klebanov, and N. Sealand. 1993. Do neighborhoods influence child and adolescent development? American Journal of Sociology 99 (2): 353-95.

Busso, M., and P. Kline. 2007. Do local economic development programs work? Evidence from the Federal Empowerment Zone program. University of California at Berkeley. Working Paper.

Coleman, J. S. 1966. Equality of educational opportunity: The Coleman Study. Washington, DC: U.S. Department of Health, Education and Welfare.

. 1991. Parental involvement in education. Washington, DC: U.S. Department of Education, Office of Educational Research and Improvement, Programs for the Improvement of Practice. Opinion Paper.

Clampet-Lundquist, S., G. J. Duncan, K. Edin, and J. R. Kling. 2006. Moving at risk teenagers out of high-risk neighborhoods: Why girls fare better than boys. Princeton, NJ: Princeton University, Industrial Relations Section Working Paper 509.

Clampet-Lundquist, S., and D. Massey. 2008. Neighborhood effects on economic self-sufficiency: A reconsideration of the Moving to Opportunity experiment. American Journal of Sociology 114 (1): 107-43.

Dobbie, W., and R. G. Fryer, Jr. 2009. Are high-quality schools enough to close the achievement gap? Evidence from a bold social experiment in Harlem. NBER Working Paper no. 15473. Cambridge, MA: National Bureau of Economic Research, November.

Gaviria, A., and S. Raphael. 2001. School-based peer effects and juvenile behavior. The Review of Economics and Statistics 83 (2): 257-68.

Heymann, J., and A. Fischer. 2003. Neighborhoods, health research, and its relevance to public policy. In Neighborhoods and health, ed. I. Kawachi and L. F. Berkman, 335-48. New York: Oxford University Press.

Hoxby, C. 2000. Peer effects in the classroom: Learning from gender and race variation. NBER Working Paper no. W7867. Cambridge, MA: National Bureau of Economic Research, August. 
Jacob, B. A., J. Ludwig, G. J. Duncan, J. Rosenbaum, and M. Johnson. 2009a. The effects of providing housing vouchers to public housing families. University of Michigan, Department of Economics. Working Paper.

2009b. Neighborhood effects on low income families: Evidence from a randomized housing voucher in Chicago. University of Michigan, Department of Economics. Working Paper.

Jacobs, J. 1997. The use of sidewalks. In Metropolis: Center and symbol of our times, ed. P. Kasinitz, 30-45. New York: New York University Press.

Jargowsky, P. A. 1996. Poverty and place: Ghettos, barrios, and the American city. New York: Russell Sage Foundation.

2003. Stunning progress, hidden problems: The dramatic decline of concentrated poverty in the 1990s. Living cities census series. Washington, DC: Brookings Institution.

Jencks, C., and S. E. Mayer. 1990. The social consequences of growing up in a poor neighborhood. In Inner-city poverty in the United States, ed. L. E. Lynn, Jr. and M. G. H. McGeary, 111-86. Washington, DC: National Academies Press.

Kaufman, J. E., and J. E. Rosenbaum. 1992. The education and employment of low-income black youth in white suburbs. Educational Evaluation and Policy Analysis 14 (3): 229-40.

Kling, J. R., J. B. Liebman, and L. F. Katz. 2007. Experimental analysis of neighborhood effects. Econometrica 75 (1): 83-119.

Kling, J. R., J. Ludwig, and L. F. Katz. 2005. Neighborhood effects on crime for female and male youth: Evidence from a randomized housing voucher experiment. Quarterly Journal of Economics 120 (1): 87-130.

Knudson, E. I., J. J. Heckman, J. L. Cameron, and J. P. Shonkoff. 2006. Economic, neurobiological, and behavioral perspectives on building America's future workforce. Proceedings of the National Academy of Sciences of the United States of America 103 (27): 10155-62.

Krueger, A. B. 1999. Experimental estimates of education production functions. Quarterly Journal of Economics 1142 : 497-532.

Ladd, H. F. 1994. Spatially targeted economic development strategies: Do they work? Cityscape: A Journal of Policy Development and Research 1.1 (August): 193-218.

Lareau, A. 2003. Unequal childhoods: Class, race, and family life. Berkeley: University of California Press.

Lee, C.-M., D. P. Culhune, and S. M. Wachter. 1999. The differential impacts of federally assisted housing programs on nearby property values: A Philadelphia case study. Housing Policy Debate 10 (2): 75-93.

Ludwig, J., and J. Kling. 2007. Is crime contagious? Journal of Law and Economics 50 (3): 491-518.

Ludwig, J., J. Liebman, J. Kling, G. Duncan, L. Katz, R. Kessler, and L. Sanbonmatsu. 2008. What can we learn about neighborhood effects from the Moving to Opportunity experiment? American Journal of Sociology 114 (1): 144-88.

Ludwig, J., H. F. Ladd, and G. J. Duncan. 2001. Urban poverty and educational outcomes. In Brookings-Wharton papers on urban affairs, ed. W. Gale and J. Rothenberg Pack. 147-201. Washington, DC: Brookings Institution.

Luttmer, E. F. P. 2005. Neighbors as negatives: Relative earnings and well-being. The Quarterly Journal of Economics 120 (3): 963-1002.

Massey, D. 1996. The age of extremes: Concentrated affluence and poverty in the twenty-first century. Demography 33 (4): 395-412.

Massey, D. S., and N. A. Denton. 1993. American apartheid: Segregation and the making of the underclass. Cambridge, MA: Harvard University Press. 
McClure, K. 1998. Housing vouchers versus housing production: Assessing longterm costs. Housing Policy Debate 9 (2): 355-71.

Mendenhall, R., S. DeLuca, and G. Duncan. 2006. Neighborhood resources, racial segregation, and economic mobility: Results from the Gautreaux program. Social Science Research 35 (4): 892-923.

Olsen, E. 2003. Housing programs for low-income households. In Means-Tested Transfer Programs in the United States. A National Bureau of Economic Research Conference Report, ed. R. Moffitt, 365-442. Chicago: University of Chicago Press.

Orr, L. L., J. D. Feins, R. Jacob, E. Beecrof, L. Sanbonmatsu, L. Katz, J. Liebman, and J. Kling. 2003. Moving to Opportunity Interim impacts evaluation. Washington, DC: U.S. Department of Housing and Urban Development, Office of Policy Development and Research.

Park, R. E., E. W. Burgess, and R. D. McKenzie. 1967. The city [by] Robert E. Park, Ernest W. Burgess [and] Roderick D. McKenzie. (With an introduction by Morris Janowitz). Chicago: University of Chicago Press.

Rubinowitz, L. S., and J. E. Rosenbaum. 2000. Crossing the class and color lines: From public housing to white suburbia. Marketing Department, University of Chicago Press.

Sampson, R. J. 2008. Moving to inequality: Neighborhood effects and experiments meet social structure. The American Journal of Sociology 114 (1): 189-231.

Sampson, R. J., J. D. Morenoff, and F. Earls. 1999. Beyond social capital: Spatial dynamics of collective efficacy for children. American Sociological Review 64 (5): 633-60.

Sampson, R. J., J. D. Morenoff, and T. Gannon-Rowley. 2002. Assessing neighborhood effects: Social processes and new directions in research. Annual Review of Sociology 28 (August): 443-78.

Sampson, R., P. Sharkey, and S. Raudenbush. 2008. Durable effects of concentrated disadvantage on verbal ability among African-American children. Proceedings of the National Academy of Sciences 105 (3): 845-52.

Sanbonmatsu, L. 2006. Neighborhoods and academic achievement: Results from the Moving to Opportunity experiment. NBER Working Paper no. 11909. Cambridge, MA: National Bureau of Economic Research, January.

Sherman, L. W. 2001. Fair and effective policing. In Crime: Public policies for crime control, ed. J. Q. Wilson and J. Petersilia, 383-412. Oakland, CA: Institute for Contemporary Studies Press.

Shonkoff, J. P., and D. Phillips. 2000. From neurons to neighborhoods: The science of early childhood development. Washington, DC: National Academy Press.

Shroder, M., and A. Reiger. 2000. Vouchers versus production revisited. Journal of Housing Research 11 (1): 91-108.

Simmel, G. 1997. Metropolis and mental life. In Metropolis: Center and symbol of our times, ed. P. Kasinitz, 30-45. New York: New York University Press.

Small, M. L., and L. Stark. 2005. Are poor neighborhoods resource deprived? A case study of childcare centers in New York. Social Science Quarterly 86 (5): 1013-36.

Votruba, M. E., and J. R. Kling. 2008. Effects of neighborhood characteristics on the mortality of black male youth: Evidence from Gautreaux, Chicago. Social Science and Medicine 68 (5): 814-23.

Watson, T. 2009. Inequality and the measurement of residential segregation by income in American neighborhoods. NBER Working Paper no. 14908. Cambridge, MA: National Bureau of Economic Research, April. 
Wilson, W. J. 1987. The truly disadvantaged: The inner city, the underclass, and public policy. Chicago: The University of Chicago Press. Knopf.

1996. When work disappears: The world of the new urban poor. New York:

1998. The role of the environment in the black-white test score gap. In The black-white test score gap, ed. C. Jencks and M. Phillips, 501-10. Washington, DC: Brookings Institution Press.

Wirth, L. 1997. Urbanism as a way of life. In Metropolis: Center and symbol of our times, ed. P. Kasinitz, 58-84. New York: New York University Press.

Zimmer, R. W., and E. F. Toma. 2000. Peer effects in private and public schools across countries. Journal of Policy Analysis and Management. 19 (1): 75.

Zorbaugh, H. W. 1983. The Gold Coast and the slum: A sociological study of Chicago's Near North Side. Chicago: The University of Chicago Press. 